\title{
Effect of CPAP on Oxidative Stress and Circulating Progenitor Cell Levels in Sleep Patients With Apnea-Hypopnea Syndrome
}

\author{
Mora Murri PhD, Regina García-Delgado MD, José Alcázar-Ramírez MD, \\ Ana Fernández-Ramos MD, Juan Alcaide, Fernando Cardona PhD, and \\ Francisco J Tinahones MD PhD
}

\begin{abstract}
BACKGROUND: The sleep apnea-hypopnea syndrome is associated with elevated oxidative stress, which is associated with reduced levels and functional impairment of progenitor cells. OBJECTIVE: To evaluate whether one month of CPAP treatment affects circulating-progenitor-cell levels and oxidative stress in patients with sleep apnea-hypopnea syndrome. METHODS: We enrolled 13 patients with sleep apnea-hypopnea syndrome who required nasal CPAP. We evaluated whiteblood-cell oxidative stress and CD45-, CD34+, KDR+, and CD133+ cell levels via flow-cytometry, before and one month after CPAP treatment. RESULTS: Superoxide anion and hydrogen peroxide were reduced, and markers of protection against oxidative stress were increased after CPAP. Progenitor-cell levels increased significantly after CPAP. There was a significant negative correlation between $\mathrm{CD} 45-, \mathrm{CD34}+, \mathrm{KDR}+$, and $\mathrm{CD133}+$ cell levels and the severity of sleep apneahypopnea syndrome and superoxide anion. CONCLUSIONS: CD45-, CD34+, KDR+, and CD133+ cell levels rose significantly and reached values close to those in the control group after one month of CPAP. This change was accompanied by a significant decrease in oxidative stress, and no change in anthropometric or metabolic variables, including insulin resistance, weight, blood pressure, or lipid levels; consequently, the increase in progenitor-cell levels might be attributable to reduced oxidative stress. Key words: circulating progenitor cells; CPAP; oxidative stress; sleep apnea-hypopnea syndrome. [Respir Care 2011;56(11):1830-1836. (C) 2011 Daedalus Enterprises]
\end{abstract}

\section{Introduction}

The sleep apnea-hypopnea syndrome is caused by recurrent closure of the upper airway during sleep, which leads to episodes of air-flow limitation. These episodes in-

\footnotetext{
Dr Murri, Mr Alcaide, and Dr Cardona are affiliated with Laboratorio de Investigación; Drs García-Delgado and Fernández-Ramos are affiliated with Servicio de Hematología; Dr Alcázar-Ramírez is affiliated with Servicio de Neumología; and Dr Tinahones is affiliated with Servicio de Endocrinología y Nutrición, Hospital Clínico Universitario Virgen de la Victoria, Málaga, Spain. Drs Cardona and Tinahones are affiliated with Centro de Investigación Biomédica en Red Fisiopatología de la Obesidad y Nutrición, Instituto de Salud Carlos III, Málaga, Spain.
}

This research was partly supported by grant SAS PI-0326/2007 from the Andalusian Health Service, and grant SAF2006-12984 from the Spanish Ministry of Education and Science. Dr Murri was partly supported by grant BES-2007-16594, and Dr Cardona was partly supported by grant CP07/0095, from the Spanish Ministry of Education and Science. The authors have disclosed no other conflicts of interest. duce cyclical alterations of arterial oxygen saturation and desaturation, which is known as hypoxia/re-oxygenation, and frequent micro-awakenings that cause a restless sleep, excessive daytime sleepiness, and cardiovascular, respiratory, and neuropsychiatric disorders. During hypoxia/ re-oxygenation the generation of reactive oxygen species is increased. ${ }^{1}$ Reactive oxygen species production can also occur via activated inflammatory responses induced by hypoxia, ${ }^{2}$ and by an increased sympathetic tone and an elevated catecholamine level. ${ }^{3}$ As a result, the overproduction of reactive oxygen species may lead to a variety of

\footnotetext{
Correspondence: Mora Murri Pierri PhD, Laboratorio de Investigaciones Biomédicas $1^{\mathrm{a}} \mathrm{pl}$, Fundación Instituto Mediterraneo para el Avance de la Biomedicina y la Investigación Biosanitaria, Hospital Virgen de la Victoria, Campus Teatinos, s/n CP 29010 Málaga, Spain. E-mail: moramurri@gmail.com.
}

DOI: $10.4187 /$ respcare. 01081 
diseases ${ }^{4}$ depending on the cell and tissue types involved and the site of production of reactive oxygen species.

The standard therapy for sleep apnea-hypopnea syndrome, CPAP, prevents hypoxia/re-oxygenation episodes and improves sleep quality, reducing oxidative stress levels. ${ }^{5}$

Reactive oxygen species such as superoxide anion $\left(\mathrm{O}_{2}{ }^{-}\right)$ and hydrogen peroxide $\left(\mathrm{H}_{2} \mathrm{O}_{2}\right)$ play an important role in normal cell growth, differentiation, migration, senescence, and apoptosis. ${ }^{6}$ Low levels of reactive oxygen species act as signaling molecules in various intracellular processes. ${ }^{7}$ By contrast, higher levels of reactive oxygen species seem to be involved in stem/progenitor-cell senescence and apoptosis.

Sleep apnea-hypopnea syndrome is related to diverse pathologies such as hypertension, obesity, and cardiovascular disease, ${ }^{8}$ which are related to oxidative stress and to progenitor-cell levels. In summary, sleep apnea-hypopnea syndrome is associated with elevated oxidative stress. Increased levels of reactive oxygen species seem to be involved in progenitor-cell functional impairment, senescence, and apoptosis. We studied whether one month of CPAP treatment affects circulating-progenitor-cell levels and oxidative stress in patients with sleep apnea-hypopnea syndrome.

\section{Methods}

This study was approved by the ethics committee of Virgen de la Victoria Hospital, Málaga, Spain, and all participants gave informed consent.

\section{Study Design}

This was a prospective observational study. We enrolled 13 patients with sleep apnea-hypopnea syndrome who required nasal CPAP, according to established criteria. ${ }^{9} \mathrm{We}$ excluded diabetic patients who required insulin, patients who failed to complete one month of CPAP treatment, and patients whose weight changed by more than $1.5 \mathrm{~kg}$ during the study.

We recruited 14 blood donors as a healthy control group. The control subjects were men of a similar age to the sleep apnea-hypopnea syndrome patients, and had no personal or family history of cardiovascular disease, dyslipidaemia, diabetes, or sleep apnea-hypopnea syndrome, which we ruled out via overnight polysomnography (Alice 5 Diagnostic Sleep System, Philips Respironics, Murrysville, Pennsylvania).

The subjects completed a structured interview, and we recorded sex, age, medical history, drug consumption, current diseases, weight, height, waist and neck circumference, body mass index, and blood pressure. The subjects also completed the Epworth Sleepiness Scale questionnaire for the evaluation of daytime sleepiness, before and after one month of CPAP.

\section{Polysomnography}

The diagnosis of sleep apnea-hypopnea syndrome was established via overnight polysomnography (Alice 5 Diagnostic Sleep System, Philips Respironics, Murrysville, Pennsylvania), which included continuous recording of oronasal flow, thoracoabdominal movements, electrocardiography, submental and pretibial electromyography, electrooculography, electroencephalography, and arterial oxygen saturation. Apnea was defined as the absence of air flow for more than 10 seconds. Hypopnea was defined as a 50\% reduction in air flow for more than 10 seconds that resulted in arousal or oxyhemoglobin desaturation. The oxygen desaturation index was defined as the number of desaturation episodes $\geq 4 \%$ per hour. The apneahypopnea index was defined as the number of apneas plus hypopneas per hour of sleep. Sleep apnea-hypopnea syndrome was defined as an apnea-hypopnea index $\geq 10$ and pathological daytime sleepiness (Epworth Sleepiness score $>10$ points $^{9}$ ), per the Spanish consensus document ${ }^{10}$ and in accordance with the recommendations of the American Academy of Sleep Medicine. ${ }^{11}$ We calculated the percentage of time during which arterial oxygen saturation was less than $90 \%$.

\section{Blood Measurements}

We measured blood pressure twice, with the subject seated, at an interval of 5 min between measurements, at 7:20 AM. Blood pressure measurements (Elka aneroid manometric sphygmomanometer, Von Schlieben, Mannheim, Germany) were taken on the right arm, which was relaxed and supported by a table, at an angle of $45^{\circ}$ from the trunk.

Fasting venous blood samples were drawn at 7:30 AM, before and after one month of CPAP, for the analysis of biochemical markers, oxidative stress biomarkers, and circulating progenitor cells. The samples were collected in vacuum tubes, with and without ethylenediaminetetraacetic acid, and kept on ice. Some samples were centrifuged, at 4,000 revolutions $/ \mathrm{min}$ for $15 \mathrm{~min}$ at $4^{\circ} \mathrm{C}$, and plasma and serum were aliquoted and stored at $-80^{\circ} \mathrm{C}$ until analysis. Serum insulin was analyzed via immunoradiometric assay (BioSource International, Camarillo, California). We used the homeostatic-model assessment to determine insulin resistance and beta-cell function. ${ }^{12}$

\section{Oxidative Stress Biomarkers}

Oxidative stress biomarkers were analyzed in white blood cells (WBCs), neutrophils, lymphocytes, and monocytes, with previously described methods. ${ }^{13-16}$ WBCs were isolated via dextran sedimentation, followed by densitygradient centrifugation, Ficoll-Paque separation, and hypotonic lysis of contaminating red blood cells. After 
purification with 2 washing steps, $1 \times 10^{6}$ cells $/ \mathrm{mL}$ WBCs were analyzed with a dual-laser flow cytometer (FACSCalibur, Becton Dickinson, Mountain View, California). We used a forward and side scatter gate to select and analyze the different cell subpopulations. We performed test standardization, data acquisition, and data analysis with CellQuest software (Becton Dickinson, Mountain View, California).

We analyzed the cell subpopulations for mitochondrial membrane potential, reactive oxygen species, and intracellular glutathione.

Mitochondrial Membrane Potential. WBCs were incubated with Rhodamine-123 (Sigma-Aldrich, St Louis, Missouri) dissolved in methanol, at a final concentration of $5 \mu \mathrm{M}$. After incubation at $37^{\circ} \mathrm{C}$ for $30 \mathrm{~min}$ in darkness with frequent agitation, the cells were washed and resuspended in phosphate-buffered saline, then analyzed with the flow cytometer.

Reactive Oxygen Species. For the assessment of mitochondrial reactive oxygen species, such as superoxide anion and hydrogen peroxide, cells were incubated with dihydroethidium (hydroethidine) $5 \mu \mathrm{M}$ stabilized solution in dimethyl sulfoxide (Molecular Probes, Eugene, Oregon) (final concentration $4 \mu \mathrm{M}$ ) and 5-(and-6)-chloromethyl$2^{\prime}, 7^{\prime}$-dichlorodihydrofluorescein diacetate, acetyl ester (Molecular Probes, Eugene, Oregon) dissolved in dimethyl sulfoxide at a final concentration $1 \mu \mathrm{g} / \mu \mathrm{L}$ ), respectively, at $37^{\circ} \mathrm{C}$ for $30 \mathrm{~min}$ in darkness with frequent agitation. The cells were then washed and re-suspended in phosphatebuffered saline, then analyzed with the flow cytometer.

Intracellular Glutathione. WBCs were incubated with 5-chloromethylfluorescein diacetate (CellTracker Green CMFDA, Molecular Probes, Eugene, Oregon) dissolved in dimethyl sulfoxide at a final concentration of $1 \mu \mathrm{M}$ for $30 \mathrm{~min}$ in darkness with frequent agitation. The labeled cells were washed and re-suspended in phosphate-buffered saline, then analyzed with the flow cytometer.

\section{Circulating Progenitor Cells}

WBCs were isolated as described above. $1 \times 10^{6}$ cells $/ \mathrm{mL}$ WBCs were treated with phosphate-buffered saline containing $20 \%$ heat-inactivated pooled normal human serum for $15 \mathrm{~min}$ at $4^{\circ} \mathrm{C}$, to saturate sites for nonspecific binding. The samples were washed with phosphate-buffered saline containing $0.5 \%$ bovine serum albumin. The blood cells were then stained with fluorescein-isothiocyanateconjugated anti-human CD34 monoclonal antibody (Becton Dickinson, Heidelberg, Germany); allophycocyaninconjugated anti-human KDR monoclonal antibody (Becton Dickinson, Heidelberg, Germany); and phycoerythrin anti-
Table 1. Characteristics at Baseline*

\begin{tabular}{lcc}
\hline \hline & $\begin{array}{c}\text { Patients } \\
(n=13)\end{array}$ & $\begin{array}{c}\text { Controls } \\
(n=14)\end{array}$ \\
\hline Age $(\mathrm{y})$ & $47.5 \pm 10.2$ & $45.8 \pm 8.8$ \\
Body mass index $\left(\mathrm{kg} / \mathrm{m}^{2}\right)$ & $31.2 \pm 6.8$ & $30.4 \pm 2.3$ \\
Systolic blood pressure $(\mathrm{mm} \mathrm{Hg})$ & $133 \pm 24$ & $121 \pm 12$ \\
Diastolic blood pressure $(\mathrm{mm} \mathrm{Hg})$ & $82 \pm 12$ & $80 \pm 9$ \\
Waist circumference $(\mathrm{cm})$ & $110 \pm 13$ & $104 \pm 9$ \\
Neck circumference $(\mathrm{cm})$ & $42 \pm 3$ & $40 \pm 3$ \\
Apnea-hypopnea index $(\mathrm{events} / \mathrm{h})$ & $52.7 \pm 17.2$ & $3.2 \pm 0.8$ \\
Mean $\mathrm{S}_{\mathrm{pO}_{2}}(\%)$ & $93 \pm 3$ & $96 \pm 1$ \\
Oxygen desaturation index & $42 \pm 22$ & $3 \pm 2$ \\
Percent of time with $\mathrm{S}_{\mathrm{pO}}<90 \%$ & $17 \pm 20$ & 0 \\
Epworth Sleepiness Scale score & $13.4 \pm 6.4$ & $3.1 \pm 1.3$ \\
& & \\
\hline All the subjects were male. The values are mean $\pm \mathrm{SD}$. & \\
\hline
\end{tabular}

human CD133 (prominin I), peridinin-chlorophyll-proteincomplex (PerCP)-conjugated anti-CD45 antibody (Abcam, Cambridge, United Kingdom). Control isotype immunoglobulin G1 and immunoglobulin G2a antibodies were used (Becton Dickinson, Heidelberg, Germany). All antibodies were incubated for $30 \mathrm{~min}$ at $4^{\circ} \mathrm{C}$, then analyzed with the flow cytometer. Circulating progenitor cells were defined as $\mathrm{CD} 45-, \mathrm{CD} 34+, \mathrm{KDR}+$, and $\mathrm{CD} 133+$.

\section{Statistical Analysis}

The results are given as mean \pm SD. Clinical variables are summarized with descriptive statistics. We analyzed the relationships of cellular oxidative stress markers and progenitor-cell levels with the Mann-Whitney U test. We compared oxidative stress, progenitor-cell levels, and clinical variables before and after CPAP with the Wilcoxon test for paired samples. We calculated the Spearman correlation coefficient to estimate the linear correlations between variables. In all cases, the rejection level for a null hypothesis was alpha $=.05$ with 2 tails. The analysis was done with statistics software (SPSS 15.0, SPSS, Chicago, Illinois).

\section{Results}

\section{Clinical and Biological Variables}

Table 1 shows the cohort's baseline characteristics. There were no significant changes in the patients after one month of CPAP (Table 2).

\section{Flow Cytometry}

The control group had significantly higher mitochondrial membrane potential and neutrophil intracellular glutathione, and significantly lower superoxide anion in most 
Table 2. Characteristics Before Versus After One Month of CPAP

\begin{tabular}{lcc}
\hline \hline & $\begin{array}{c}\text { Before CPAP } \\
(\text { mean } \pm \mathrm{SD})\end{array}$ & $\begin{array}{c}\text { After CPAP } \\
(\text { mean } \pm \mathrm{SD} \text { )* }\end{array}$ \\
\hline Epworth Sleepiness Scale score & $13.4 \pm 6.4$ & $10.9 \pm 5.2$ \\
Systolic blood pressure (mm Hg) & $133 \pm 24$ & $124 \pm 15$ \\
Diastolic blood pressure (mm Hg) & $82 \pm 12$ & $74 \pm 22$ \\
Insulin ( $\mu \mathrm{IU} / \mathrm{mL})$ & $17.7 \pm 8.1$ & $17.2 \pm 8.8$ \\
Insulin resistance & $7.0 \pm 5.6$ & $5.7 \pm 3.7$ \\
Beta-cell function & $95.2 \pm 65.5$ & $81.7 \pm 46.4$ \\
Triglyceride (mg/dL) & $166 \pm 112$ & $170 \pm 125$ \\
Cholesterol (mg/dL) & $207 \pm 28$ & $203 \pm 33$ \\
High-density lipoprotein C (mg/dL) & $45 \pm 13$ & $45 \pm 15$ \\
Low-density lipoprotein C (mg/dL) & $140 \pm 20$ & $136 \pm 22$ \\
\end{tabular}

* None of the differences are significant.

Table 3. White Blood Cell Oxidative Stress Markers

\begin{tabular}{|c|c|c|c|}
\hline & $\begin{array}{c}\text { Patients } \\
\text { (mean } \pm \mathrm{SD})\end{array}$ & $\begin{array}{c}\text { Controls } \\
\text { (mean } \pm \mathrm{SD})\end{array}$ & $P^{*}$ \\
\hline \multicolumn{4}{|c|}{$\begin{array}{l}\text { Mitochondrial Membrane } \\
\text { Potential }\end{array}$} \\
\hline Lymphocytes & $22.0 \pm 3.8$ & $16.6 \pm 3.3$ & $<.001$ \\
\hline Monocytes & $41.8 \pm 7.5$ & $34.1 \pm 7.4$ & .009 \\
\hline Neutrophils & $30.2 \pm 7.3$ & $22.5 \pm 3.8$ & $<.001$ \\
\hline Total leukocytes & $32.1 \pm 7.7$ & $21.2 \pm 3.7$ & $<.001$ \\
\hline \multicolumn{4}{|l|}{ Hydrogen Peroxide } \\
\hline Lymphocytes & $14.6 \pm 3.3$ & $16.0 \pm 5.2$ & .19 \\
\hline Monocytes & $25.2 \pm 3.5$ & $39.4 \pm 17.2$ & .08 \\
\hline Neutrophils & $22.4 \pm 5.8$ & $24.1 \pm 9.1$ & .41 \\
\hline Total leukocytes & $22.8 \pm 7.0$ & $22.5 \pm 8.2$ & $>.99$ \\
\hline \multicolumn{4}{|l|}{ Superoxide Anion } \\
\hline Lymphocytes & $13.4 \pm 2.0$ & $16.8 \pm 3.6$ & .009 \\
\hline Monocytes & $22.1 \pm 3.8$ & $34.8 \pm 9.2$ & $<.001$ \\
\hline Neutrophils & $18.9 \pm 2.9$ & $24.5 \pm 11.0$ & .058 \\
\hline Total leukocytes & $18.3 \pm 4.1$ & $22.1 \pm 6.7$ & .24 \\
\hline \multicolumn{4}{|c|}{ Intracellular Glutathione } \\
\hline Lymphocytes & $175.1 \pm 25.6$ & $184.5 \pm 190.2$ & .052 \\
\hline Monocytes & $490.2 \pm 106.2$ & $366.8 \pm 158.4$ & .052 \\
\hline Neutrophils & $542.8 \pm 95.1$ & $294.8 \pm 135.5$ & $<.001$ \\
\hline Total leukocytes & $344.5 \pm 96.1$ & $251.3 \pm 143.7$ & .07 \\
\hline
\end{tabular}

cell types (Table 3). Superoxide anion and hydrogen peroxide were reduced and intracellular glutathione level was increased after CPAP treatment. These redox changes were accompanied by an increase in the mitochondrial membrane potential. Figure 1 shows the oxidative stress biomarkers measurements before and after CPAP treatment. There was a significant decrease in the superoxide anion and hydrogen peroxide levels in all the cell types studied. There was a significant increase in the mitochondrial membrane potential in all cell types, and in intracellular gluta-
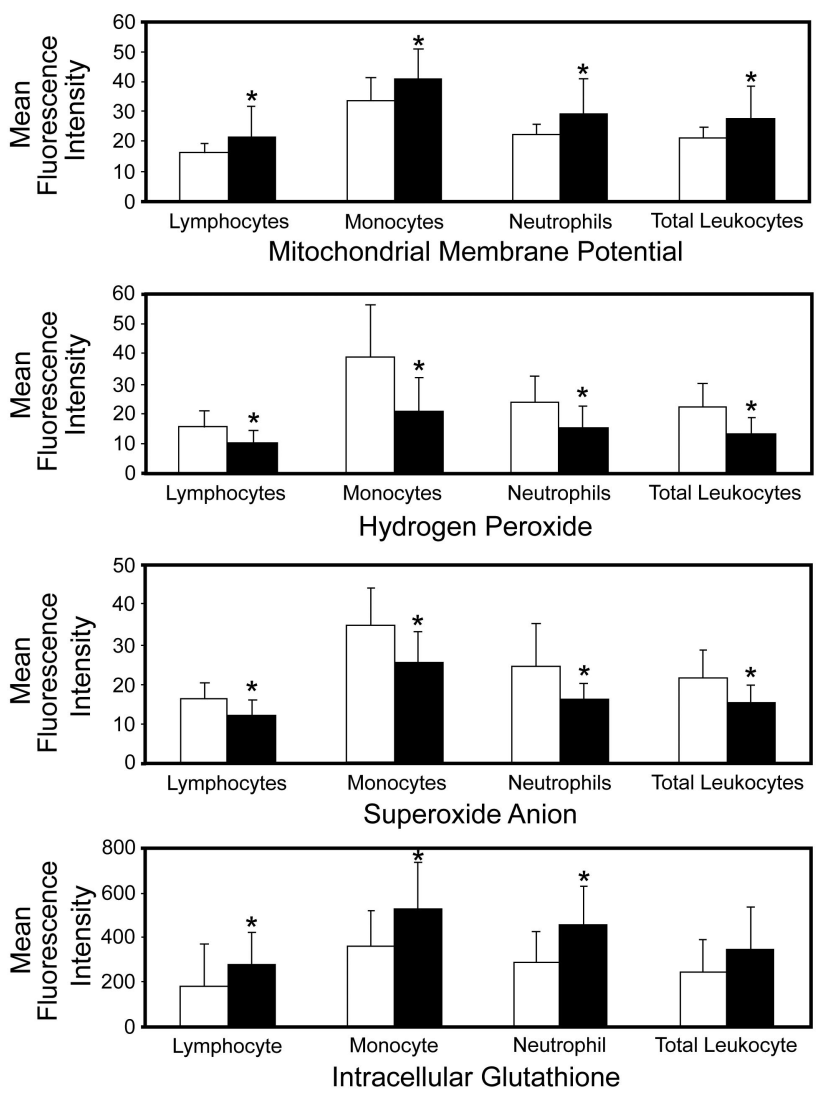

Fig. 1. Relationships between cellular oxidative stress markers in patients before and after one month of CPAP treatment. A: Mitochondrial membrane potential. B: Hydrogen peroxide. C: Superoxide anion. D: Intracellular glutathione. *Significant difference via Wilcoxon test.

thione levels in lymphocytes, monocytes, and neutrophils. The circulating-progenitor-cell levels were higher in the controls than in the patients, and circulating-progenitorcell level increased significantly after CPAP treatment (Fig. 2).

\section{Correlation Analysis}

Before CPAP treatment there were significant correlations between apnea-hypopnea index and the hydrogen peroxide levels in lymphocytes, monocytes, and total leukocytes (Fig. 3).

Before CPAP there was a significant negative correlation between circulating-progenitor-cell levels and apneahypopnea index $(\mathrm{r}=-0.629, P=.02)$, and between circulating-progenitor-cell levels and oxidative stress biomarkers (Table 4).

\section{Discussion}

The novelty of this study is that circulating-progenitorcell levels and oxidative stress were evaluated in periph- 


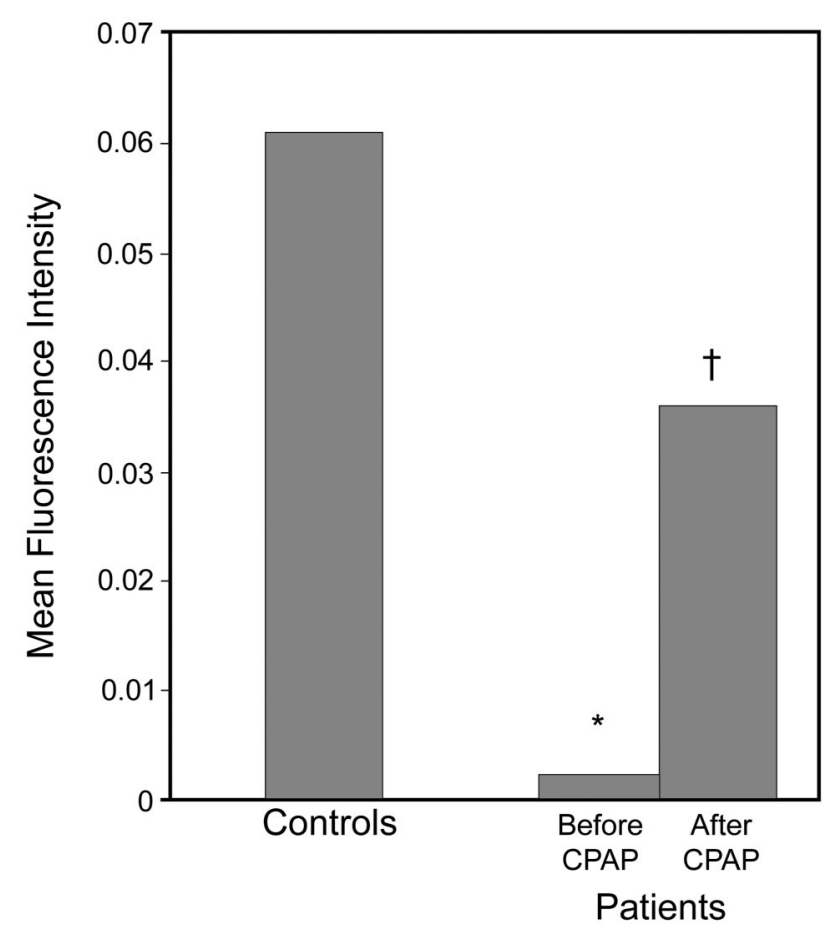

Fig. 2. CD45-, CD34+, KDR +, and CD133+ cell levels in controls and patients before and after one month of CPAP treatment. ${ }^{*} P<.001$ (via Mann-Whitney $U$ test) for controls versus patients before CPAP. $\dagger P=.002$ (via Wilcoxon test for paired data) for patients before versus after CPAP.

eral cells from patients with sleep apnea-hypopnea syndrome, and we considered other pathologies usually associated with sleep apnea-hypopnea syndrome, such as insulin resistance, hypertension, and obesity. Recently, Jelic et al described how sleep apnea-hypopnea syndrome directly affects the vascular endothelium by promoting inflammation and oxidative stress, and that effective CPAP therapy is associated with reversal of those alterations. ${ }^{17}$ However, those authors did not analyze whether their subjects were insulin resistant. Thus, our study complements previous studies.

The present study confirms that, compared to controls, patients with sleep apnea-hypopnea syndrome have elevated cellular markers of oxidative stress. Sleep apneahypopnea syndrome is characterized by long-term sleep deprivation, which increases reactive oxygen species generation, inhibits antioxidant defense systems, and inactivates mitochondrial enzymes, thereby promoting oxidative stress. ${ }^{18}$

In our subjects, CPAP reduced cellular oxidative stress variables and increased intracellular glutathione and mitochondrial membrane potential, which are markers of protection against oxidative stress. These results confirm that normalizing hypoxia with CPAP reduces oxidative stress. ${ }^{2,19}$ Recent studies found an association between sleep apnea-hypopnea syndrome and oxidative stress, ${ }^{3}$ and we found a significant positive correlation
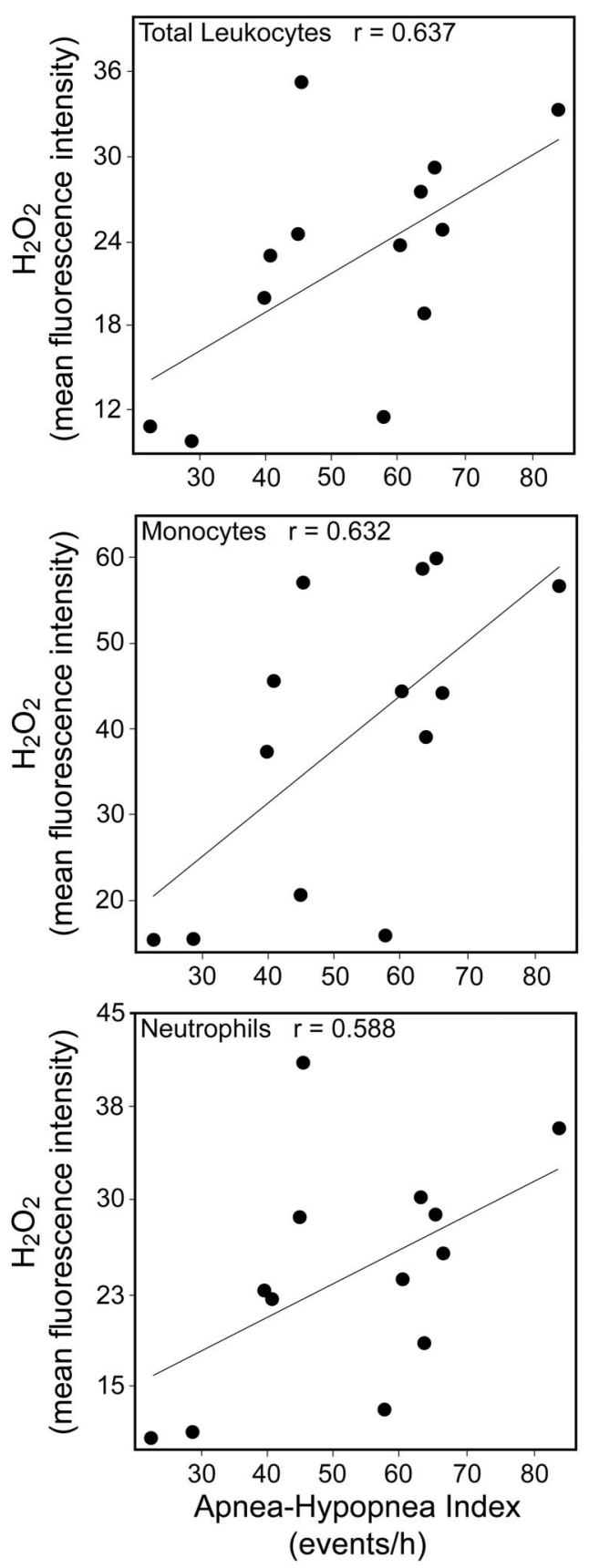

Fig. 3. Spearman's correlation coefficients $(r)$ between apneahypopnea index and hydrogen peroxide $\left(\mathrm{H}_{2} \mathrm{O}_{2}\right)$ level in total leukocytes, monocytes, and neutrophils, before CPAP treatment.

between hydrogen peroxide levels and apnea-hypopnea index before CPAP treatment.

We analyzed circulating-progenitor-cell levels, and the cells that showed the most significant changes were CD45-, CD34+, KDR +, and CD133+ cells, which were lower in the patients with sleep apnea-hypopnea syndrome than in the controls. The levels rose significantly after $\mathrm{CPAP}$, accompanied by reduction in oxidative stress. 
Table 4. Correlations* Between CD45-, CD34+, KDR + , and

CD133+ Cell Levels and Cellular Oxidative Stress

Markers

\begin{tabular}{lcc}
\hline \hline & $\mathrm{r}$ & $P$ \\
\hline Mitochondrial Membrane & & \\
$\quad$ Potential & & \\
Lymphocytes & 0.587 & .001 \\
Monocytes & 0.449 & .02 \\
Neutrophils & 0.664 & $<.001$ \\
$\quad$ Total leukocytes & 0.617 & $<.001$ \\
Hydrogen Peroxide & & \\
Lymphocytes & -0.312 & .11 \\
Monocytes & -0.352 & .07 \\
Neutrophils & -0.225 & .25 \\
Total leukocytes & -0.107 & .59 \\
Superoxide Anion & & .006 \\
Lymphocytes & -0.504 & .001 \\
Monocytes & -0.607 & .03 \\
Neutrophils & -0.409 & .08 \\
Total leukocytes & -0.340 & .03 \\
Intracellular Glutathione & & .053 \\
Lymphocytes & 0.403 & .001 \\
Monocytes & 0.370 & \\
Neutrophils & 0.658 & \\
Total leukocytes & 0.356 & \\
\end{tabular}

* Spearman correlation coefficient.

Our population cell levels were linked to sleep apneahypopnea syndrome severity: greater severity correlated with lower levels of these cells. Hypoxia/re-oxygenation induces damage and apoptosis in human cells, ${ }^{20}$ and continuous cycles of hypoxia/re-oxygenation can increase the production of oxidants. ${ }^{18} \mathrm{We}$ found that markers of protection against oxidation correlated positively with the levels of CD45-, CD34+, KDR+, and CD133+ cells, whereas the levels of superoxide anion correlated negatively. After one month of CPAP treatment, oxidative stress variables decreased and $\mathrm{CD} 45-, \mathrm{CD} 34+, \mathrm{KDR}+$, and $\mathrm{CD} 133+$ cell levels increased. There is increasing evidence that oxidative stress reduces and impairs these cells' functioning. ${ }^{21}$ Thum et $\mathrm{al}^{22}$ found that increased production of reactive oxygen species was associated with reduced progenitor-cell levels and impaired progenitor-cell function. Similarly, another study found that incubation of progenitor cells with high levels of $\mathrm{H}_{2} \mathrm{O}_{2}$ profoundly reduced their number by inducing apoptosis. ${ }^{23}$ These observations were supported by the finding that glutathione peroxidase-1-deficient mice exhibited a reduced number and functional activity of progenitor cells. ${ }^{24}$ Thus, it is clear that conditions associated with increased oxidative stress decrease the absolute numbers of circulating progenitor cells and impair progenitor-cell function, with deleterious effects on vascular homeostasis.

\section{Conclusions}

After one month of CPAP treatment the CD45-, $\mathrm{CD} 34+, \mathrm{KDR}+$, and $\mathrm{CD} 133+$ cell levels in the patient group rose significantly (to near those in the control group) and there was a significant decrease in oxidative stress, with no change in anthropometric or metabolic variables. Patients in our study were mostly obese, hypertensive, dyslipidemic, and insulin-resistant. CPAP was not associated with significant changes in insulin resistance, weight, blood pressure or lipid level, so the increase in the CD45-, $\mathrm{CD} 34+, \mathrm{KDR}+$, and $\mathrm{CD} 133+$ cell levels is probably related to the reduction in oxidative stress.

We believe that a better understanding of how CPAP treatment affects oxidative stress and circulating progenitor cells would provide additional insight into the pathogenesis of sleep apnea-hypopnea syndrome.

\section{REFERENCES}

1. Babior BM. Phagocytes and oxidative stress. Am J Med 2000;109(1): 33-44.

2. Dyugovskaya L, Lavie P, Lavie L. Increased adhesion molecules expression and production of reactive oxygen species in leukocytes of sleep apnea patients. Am J Respir Crit Care Med 2002;165(7): 934-939.

3. Singal PK, Kapur N, Dhillon KS, Beamish RE, Dhalla NS. Role of free radicals in catecholamine-induced cardiomyopathy. Can J Physiol Pharmacol 1982;60(11):1390-1397.

4. Suzuki YJ, Jain V, Park AM, Day RM. Oxidative stress and oxidant signaling in obstructive sleep apnea and associated cardiovascular diseases. Free Radic Biol Med 2006;40(10):1683-1692.

5. Hernández C, Abreu J, Abreu P, Colino R, Jiménez A. Effects of nasal positive airway pressure treatment on oxidative stress in patients with sleep apnea-hypopnea syndrome. Arch Bronconeumol 2006;42(3):125-129

6. Ushio-Fukai M, Urao N. Novel role of NADPH oxidase in angiogenesis and stem/progenitor cell function. Antioxid Redox Signal 2009;11(10):2517-33.7.

7. D'Autréaux B, Toledano MB. ROS as signalling molecules: mechanisms that generate specificity in ROS homeostasis. Nat Rev Mol Cell Biol 2007;8(10):813-824.

8. Ozol D, Turkay C, Kasapoglu B, Karamanlı H, Yıldırım Z. Relationship between components of metabolic syndrome and polysomnographic findings in obstructive sleep apnea. Metab Syndr Relat Disord 2011;9(1):13-18

9. Kapuniai LE, Andrew DJ, Crowell DH, Pearce JW. Identifying sleep apnea from self-reports. Sleep 1988;11(5):430-436.

10. Chiner E, Arriero JM, Signes-Costa J, Marco J, Fuentes I. Validation of the Spanish version of the Epworth Sleepiness Scale in patients with a sleep apnea syndrome. Arch Bronconeumol 1999;5(9): 422-427.

11. American Academy of Sleep Medicine. International classification of sleep disorders: diagnostic and coding manual. Westchester, IL: American Academy of Sleep Medicine; 2005.

12. Matthews DR, Hosker JP, Rudenski AS, Naylor BA, Treacher DF, Turner RC. Homeostasis model assessment: insulin resistance and beta-cell function from fasting plasma glucose and insulin concentrations in man. Diabetologia 1985;28(7):412-419. 


\section{CPaP, Oxidative Stress, and Circulating Progenitor Cells}

13. Shang XJ, Yao G, Ge JP, Sun Y, Teng WH, Huang YF. Procyanidin induces apoptosis and necrosis of prostate cancer cell line PC-3 in mitochondrion-dependent manner. J Androl 2009;30(2):122-126.

14. Barbacanne MA, Souchard JP, Darblade B, Iliou JP, Nepveu F, Pipy $\mathrm{B}$, et al. Detection of superoxide anion released extracellularly by endothelial cells using cytochrome c reduction, ESR, fluorescence and lucigenin-enhanced chemiluminescence techniques Free Radic Biol Med 2000;29(5):388-396.

15. LeBel CP, Ischiropoulos H, Bondy SC. Evaluation of the probe $2^{\prime}, 7^{\prime} \mathrm{di}-$ chlorofluorescein as an indicator of reactive oxygen species formation and oxidative stress. Chem Res Toxicol 1992;5(2):227-231.

16. Sebastià J, Cristòfol R, Martín M, Rodríguez-Farré E, Sanfeliu C. Evaluation of fluorescent dyes for measuring intracellular glutathione content in primary cultures of human neurons and neuroblastoma SH-SY5Y. Cytometry A 2003;51(1):16-25.

17. Jelic S, Padeletti M, Kawut SM, Higgins C, Canfield SM, Onat D, et al. Inflammation, oxidative stress, and repair capacity of the vascular endothelium in obstructive sleep apnea. Circulation 2008; 117(17):2270-2278

18. Zhang X, Li J, Sejas DP, Pang Q. Hypoxia-reoxygenation induces premature senescence in FA bone marrow hematopoietic cells. Blood 2005;106(1):75-85.

19. Murri M, Alcázar-Ramírez J, Garrido-Sánchez L, Linde F, Alcaide J, Cardona F, Tinahones FJ. Oxidative stress and metabolic changes after continuous positive airway pressure treatment according to previous metabolic disorders in sleep apnea-hypopnea syndrome patients. Transl Res 2009;154(3):111-121.

20. Dhar-Mascareño M, Cárcamo JM, Golde DW. Hypoxia-reoxygenation-induced mitochondrial damage and apoptosis in human endothelial cells are inhibited by vitamin C. Free Radic Biol Med 2005; 38(10):1311-1322.

21. Tousoulis D, Andreou I, Antoniades C, Tentolouris C, Stefanadis C. Role of inflammation and oxidative stress in endothelial progenitor cell function and mobilization: therapeutic implications for cardiovascular diseases. Atherosclerosis 2008;201(2):236-247.

22. Thum T, Fraccarollo D, Schultheiss M, Froese S, Galuppo P, Widder $\mathrm{JD}$, et al. Endothelial nitric oxide synthase uncoupling impairs endothelial progenitor cell mobilization and function in diabetes. Diabetes 2007;56(3):666-674.

23. Urbich C, Knau A, Fichtlscherer S, Walter DH, Brühl T, Potente M, et al. FOXO-dependent expression of the proapoptotic protein Bim: pivotal role for apoptosis signaling in endothelial progenitor cells. FASEB J 2005;19(8):974-976.

24. Galasso G, Schiekofer S, Sato K, Shibata R, Handy DE, Ouchi N, et al. Impaired angiogenesis in glutathione peroxidase-1-deficient mice is associated with endothelial progenitor cell dysfunction. Circ Res 2006;98(2):254-261. 